\title{
The Role of Nonheme Transition Metal-Oxo, -Peroxo, and - Superoxo Intermediates in Enzyme Catalysis and Reactions of Bioinspired Complexes
}

DOI:

10.1016/bs.adioch.2017.01.002

\section{Document Version}

Accepted author manuscript

Link to publication record in Manchester Research Explorer

Citation for published version (APA):

Faponle, A. S., \& de Visser, S. P. (2017). The Role of Nonheme Transition Metal-Oxo, -Peroxo, and -Superoxo Intermediates in Enzyme Catalysis and Reactions of Bioinspired Complexes. Advances in Inorganic Chemistry, 70. https://doi.org/10.1016/bs.adioch.2017.01.002

Published in:

Advances in Inorganic Chemistry

\section{Citing this paper}

Please note that where the full-text provided on Manchester Research Explorer is the Author Accepted Manuscript or Proof version this may differ from the final Published version. If citing, it is advised that you check and use the publisher's definitive version.

\section{General rights}

Copyright and moral rights for the publications made accessible in the Research Explorer are retained by the authors and/or other copyright owners and it is a condition of accessing publications that users recognise and abide by the legal requirements associated with these rights.

\section{Takedown policy}

If you believe that this document breaches copyright please refer to the University of Manchester's Takedown Procedures [http://man.ac.uk/04Y6Bo] or contact uml.scholarlycommunications@manchester.ac.uk providing relevant details, so we can investigate your claim.

\section{OPEN ACCESS}


The Role of Nonheme Transition Metal-Oxo, -Peroxo and -Superoxo Intermediates in Enzyme Catalysis and Reactions of Bio-Inspired Complexes.

Abayomi S. Faponle and Sam P. de Visser*

Manchester Institute of Biotechnology and School of Chemical Engineering and Analytical Science, The University of Manchester, 131 Princess Street, Manchester M1 7DN (United Kingdom). 
Abstract: Transition metals are common co-factors in enzymes and enable catalysis to take place via reaction barriers that are accessible at room temperature. Oxygen activating metalloenzymes are versatile species in Nature involved in vital processes ranging from biodegradation to biosynthesis. Since oxygen activating intermediates are not readily amenable to experimental study, research has started to focus on biomimetic model systems that have the active site coordination sphere and structural features, but react in solution. In our research group, we have been involved in computational modeling of heme and nonheme iron dioxygenases as well as biomimetic models of these complexes. In this contribution an overview is given on recent results of the characterization and reactivity patterns of metaloxo, metal-peroxo and metal-superoxo complexes. In particular, in recent studies attempts were made to trap and characterize the short-lived oxygen bound intermediate in the catalytic cycle of cysteine dioxygenase. Many suggested structures could be ruled out by theoretical considerations, yet these also provided suggestions of possible candidates for the experimentally observed spectra. In addition, we review recent studies on the nonheme iron(III)-hydroperoxo species and how its reactivity patterns with arenes are dramatically different from those found for heme iron(III)-hydroperoxo species. The final two projects show a series of computational studies on manganese(V)-oxo and side-on manganese(III)peroxo moieties that identify a unique spin state reactivity pattern with a surprising product distribution. 


\section{Introduction}

Oxygen activation by enzymes is one of the most common biochemical reactions in Nature whereby one or both oxygen atoms of $\mathrm{O}_{2}$ are donated into a substrate. Many of these monoxygenase and dioxygenase enzymes employ transition metal centers to perform this catalytic reaction. ${ }^{1{ }^{7}}$ In monoxygenases one oxygen atom of $\mathrm{O}_{2}$ is inserted into the substrate, whereas the other oxygen atom is reduced to water, ${ }^{8-12}$ while in dioxygenases both oxygen atoms are inserted into one or more substrates. ${ }^{3,6,13,14}$ As molecular oxygen is in a triplet spin ground state and organic substrates typically are in a singlet spin state, it has been hypothesized that these enzymes enable an otherwise spin-forbidden reaction. ${ }^{4}$ These oxidants enable this reaction due to the involvement of a transition metal with virtual or partially occupied valence orbital sub-shells. However, in recent years several co-factor independent dioxygenases have been trapped and characterized that are able to transfer triplet dioxygen into a closed-shell singlet substrate without the assistance of a transition metal center. For instance, the enzyme 1-H-3-hydroxy-4-oxoquinaldine 2,4-dioxygenase performs an intradiol-type dioxygenation of an aromatic substrate in the absence of co-factor although the reaction is slow. ${ }^{15,16}$ Therefore, co-factors, such as transition metals in metalloenzymes, are expected to speed up biochemical reactions significantly by lowering the rate determining energy barrier in a reaction mechanism. Metalloenzymes can be mononuclear or binuclear or contain more than two metal centers, ${ }^{17}$ however, in this review we will focus on mononuclear iron complexes only.

A common structural motif in mononuclear nonheme iron dioxygenases is an active site where the iron is bound to two histidine and one carboxylate amino acid side chain in a facial 2-His/1-Asp ligand feature. ${ }^{7,18}$ In Figure 1, the active site of the nonheme iron dioxygenase 
taurine/ $\alpha$-ketoglutarate $(\alpha-K G)$ dependent dioxygenase (TauD) is depicted and shows its typical structural motif with the metal bound to the 2-His/1-Asp ligand environment, where the iron interacts with the side chains of His99, Asp $_{101}$ and $\mathrm{His}_{255}$. The structure shown in Figure 1 is taken from the protein data bank (pdb) with identifier 1 OS7. ${ }^{19}$ In the active site, the metal iron center is in a pentadentate coordination and thus is anchored to the two imidazolium groups of the posttranslationally modified histidine residues and the carboxylic group of aspartate. The fourth and fifth ligand positions of the metal are occupied by the carboxylic acid and keto group of $\alpha-\mathrm{KG}$ co-substrate. TauD is involved in the hydroxylation of taurine, which is a step in the biodegradation of cysteine in the body.

[Figure 1 near here]

TauD undergoes a catalytic cycle that starts off from an iron(II) resting state (A), where the metal is bound to the 2-His/1-Asp ligand system and three water molecules. Binding of $\alpha-\mathrm{KG}$ displaces two water molecules and subsequently dioxygen replaces the final one to form the elusive iron(III)-superoxo complex (B). This intermediate reacts with $\alpha$-KG by decarboxylation and the formation of an iron(IV)-oxo (C), succinate and $\mathrm{CO}_{2}$. The iron(IV)oxo species of TauD has been characterized with UV-Vis, electron paramagnetic resonance (EPR) and Mössbauer spectroscopic measurements and shown to be in a quintet spin ground state. ${ }^{20}$ Kinetic isotope effect studies using deuterated taurine gave evidence of a rate determining hydrogen atom abstraction leading to an iron(III)-hydroxo intermediate (D) that after $\mathrm{OH}$ rebound gives the alcohol product complexes. Computational studies, initially with small active site models of TauD confirmed the catalytic cycle and showed the oxygen activation to be a strong exothermic process with the most stable structure being the iron(IV)oxo intermediate. ${ }^{21,22}$ Subsequently, quantum mechanics/molecular mechanics (QM/MM) studies on nonheme iron dioxygenases TauD, and AlkB (the later are DNA repair enzymes) were performed that took the complete protein environment into consideration. ${ }^{23,24}$ Although 
the protein environment affects the barrier heights along the reaction mechanism dramatically, the work on TauD of QM/MM versus active site models gave the same overall conclusions. However, AlkB was shown to proceed with a catalytic cycle that showed a major difference to that found for TauD, namely, the iron(IV)-oxo species was found to undergo a $90^{\circ}$ rotation during the catalytic cycle prior to the hydrogen atom abstraction step. It was hypothesized that this unusual rotation is essential to keep the dioxygen binding and substrate binding separate.

[Figure 2 near here]

Further computational modeling of the high-valent iron(IV)-oxo intermediate nonheme iron dioxygenases including TauD and prolyl-4-hydroxylase $(\mathrm{P} 4 \mathrm{H})$ was performed in our group. ${ }^{25}{ }^{30}$ The studies show that the pentacoordinate nonheme iron(IV)-oxo complex is an extremely powerful oxidant that reacts with substrates with significantly lower hydrogen atom abstraction barriers than heme iron(IV)-oxo cation radical (Compound I, (CpdI)) species as found in cytochrome $\mathrm{P} 450$.

Interestingly, in the nonheme iron dioxygenases cysteine dioxygenase $(\mathrm{CDO})^{31,32}$ and ergothionine synthase $(\mathrm{EgtB}),{ }^{33,34}$ the metal is bound to a 3-His motif rather than 2-His/1Asp. An extensive set of computational studies on CDO enzymes ${ }^{35} 37$ and model complexes was performed. ${ }^{38,39}$ The calculations showed that the 3-His ligand system in CDO is essential for complete dioxygenase activity and significant amount of cysteine sulfoxide product is predicted in $\mathrm{CDO}$ with a 2-His/1-Asp ligand system. Furthermore, the ligand environment is important for spin state ordering and catalysis. Thus, in TauD the ground state of the iron(III)-superoxo is quintet spin and during the oxygen activation mechanism the system stays in the quintet spin state. In CDO the spin state ordering varies strongly and is dependent 
on the model and method used in the calculations. Nevertheless, the rate determining barriers all proceed on a dominant quintet spin state surface.

By contrast to the nonheme iron dioxygenases, the heme monoxygenases, such as the cytochrome P450 enzymes, have been well studied for oxidation reactions. ${ }^{40 \_42}$ In the human body, the cytochromes P450 play crucial roles particularly in the liver where they are involved in the metabolism of xenobiotics and drug molecules. Furthermore, the P450s have been implicated in biosynthesis pathways for the synthesis of estrogen and other hormones. As such, metalloenzymes have large differences in their ligand environment and chemical structure and hence show a wide variety of chemical and biological functions.

In most metal-heme dependent enzymes, including monoxygenases such as the P450s as well as heme peroxidases and catalases, ${ }^{43}$ the catalytic cycle passes a high-valent iron(IV)-oxo $\pi$ cationic radical intermediate called Compound I (CpdI). In all of these, $\mathrm{CpdI}$ is generated in a catalytic cycle that requires two electron reductions and two proton transfers as summarized in Eq 1. This is in contrast to the above mentioned nonheme iron dioxygenases that generate their iron(IV)-oxo species through the assistance of a co-substrate, such as $\alpha-\mathrm{KG}$.

iron(III)-heme $+\mathrm{O}_{2}+2 \mathrm{H}^{+}+2 \mathrm{e}^{-} \rightarrow \operatorname{iron}(\mathrm{IV})$-oxo-heme $(+\bullet)+\mathrm{H}_{2} \mathrm{O}$

Structurally, the iron-heme group in the P450s is bound to the protein through a covalent linkage of the iron with a cysteinate sidechain, whereas catalases bind a tyrosinate group and the peroxidases typically a histidine group. It has been proposed that the nature of the axial ligand affects and guides the reactivity patterns and gives the heme enzyme its unique chemical properties. Indeed computational modeling of propene activation by models of P450 CpdI with peroxidase and catalase models of CpdI showed higher reactivity of the P450 
system by orders of magnitude. ${ }^{44 \_49}$ This is due to the fact that the highest occupied molecular orbital, the $\mathrm{a}_{2 \mathrm{u}}$ orbital, in P450 CpdI is a mixed porphyrin/axial ligand orbital and the amount of mixing is dependent on the electron-donating properties of the axial ligand. Therefore, a stronger electron-donating group, such as $\mathrm{OH}^{-}$or $\mathrm{SH}^{-}$yields an increase of the $\mathrm{a}_{2 \mathrm{u}}$-antibonding combination and consequently lowers the electron affinity of the complex and makes these complexes good oxidants. By contrast, strong electron-withdrawing groups, like histidine or neutral solvent molecules, lower the $a_{2 u}$ orbitals and increase the electron affinity of the complex and hence make it a much weaker oxidant. ${ }^{50}$

Cytochrome P450 CpdI and the iron(IV)-oxo species in nonheme iron dioxygenases are versatile oxidants that react efficiently with substrates. Generally, these active catalytic intermediates of heme and nonheme enzymes are able to activate strong aliphatic $\mathrm{C}-\mathrm{H}$ bonds and convert them to alcohol groups. Other common reactions catalyzed by iron(IV)-oxo complexes include substrate epoxidation, aromatic hydroxylation, desaturation, $\mathrm{N}-$ and $\mathrm{O}-$ dealkylation, and heteroatom transfers such as sulfoxidation reactions. ${ }^{8}{ }^{10}$ Although these catalytic intermediates are implicated in many inorganic and bioinorganic reactions, spectroscopic evidence of their direct involvement in reactions is sparse as they are shortlived due to their highly reactive nature. However for the active species of the P450 catalytic cycle known as Compound I, spectroscopic evidence was obtained through UV-Vis, Electron Paramagnetic Resonance (EPR), and Mössbauer spectroscopic techniques and was reported by Rittle and Green. ${ }^{51}$ In heme and nonheme systems, the participation of a very active metaloxo center for chemical transformations is convincing; nonetheless, there is still a debate as to the catalytic efficiencies of alternative oxygen-bound iron complexes, such as iron(II)peroxo, iron(III)-superoxo and iron(III)-hydroperoxo species. For instance, the catalytic 
potency of heme mononuclear iron(III)-hydroperoxo intermediate in P450 chemistry has been disputed, as experimental and computational studies have shown that it is a sluggish oxidant in substrate oxidation of P450 catalysis, and therefore would not be the principal oxidant in hydroxylation of organic substrates. ${ }^{52-60}$ These studies contrast the findings that exist for biomimetic nonheme iron systems whereby the nonheme iron(III)-hydroperoxo species is catalytically efficient and can perform substrate activation reactions. ${ }^{61 \_65}$ In addition, although it is very difficult to trap side-on manganese-peroxo (MnOO) in spectroscopic studies, there is experimental and computational evidence of its catalytic potency in the literature particularly for synthetic biomimetic models that closely resemble enzyme intermediates. $^{4,5,7,66}$

It is clear, therefore, that nonheme and heme dioxygen bound intermediates have catalytic properties that are dramatically different and result in the nonheme iron(III)-hydroperoxo species to be catalytically active in aromatic hydroxylation reactions, while heme iron(III)hydroperoxo, by contrast, is unreactive. Computational studies give insight into the origin of these reactivity differences. In this review paper we will investigate thoroughly the catalytic and electronic properties of a variety of metal(IV)-oxo, metal(III)-peroxo, metal(III)superoxo and metal(III)-hydroperoxo species and try to understand their reactivity differences. These individual studies all have their inspiration from enzymatic catalytic cycles and particularly to the nonheme iron dioxygenases that efficiently perform oxygen insertion reactions into substrates. It is now becoming clear that not only metal(IV)-oxo is an active oxidant of oxygen atom transfer reactions but that in some cases metal(III)-superoxo or metal(III)-hydroperoxo can be as efficient - if not a better oxidant.

\section{Metal-(di)oxygen intermediates.}


As described above, the catalytic cycles of heme and nonheme iron monoxygenases and dioxygenases generally proceed through the formation of a high valent metal(IV)-oxo intermediate. For instance, in $\mathrm{TauD}^{20 \_22}$ dioxygen binds the iron(II) center as an iron(III)superoxo group that attacks the keto-position of $\alpha$-ketoglutarate to form succinate, $\mathrm{CO}_{2}$ and an iron(IV)-oxo species. The iron(IV)-oxo intermediate abstracts a hydrogen atom from the taurine substrate and after radical rebound gives hydroxylated taurine, an intermediate in the cysteine metabolism pathway in the body. In CDO, by contrast, both oxygen atoms are transferred to the substrate (cysteine) in a consecutive process via cysteine-sulfoxide to form cysteine-sulfinic acid product. ${ }^{31,32,67}$ Interestingly, the nonheme iron dioxygenase isopenicillin $\mathrm{N}$ synthase reacts with substrate through four consecutive hydrogen atom abstraction reactions. ${ }^{68,69}$ This proceeds by the formation of an iron(III)-superoxo reactant from an iron(II) resting state and molecular oxygen, which after hydrogen atom abstraction is converted into an iron(II)-hydroperoxo intermediate. The latter abstracts a hydrogen atom to form water and an iron(IV)-oxo group and leads to a ring-closure step (desaturation) of the substrate. Subsequently, another hydrogen atom abstraction by the iron(IV)-oxo species gives the iron(III)-hydroxo complex. A final hydrogen atom abstraction by the iron(III)-hydroxo species closes another ring in the substrate (desaturation) and returns the cycle to the iron(II) resting state and releases product. It appears, therefore, that in isopenicillin $\mathrm{N}$ synthase the iron(III)-superoxo, iron(II)-hydroperoxo, iron(IV)-oxo and iron(III)-hydroxo intermediates all are catalytically active oxidants that are able to react with substrates by hydrogen atom abstraction from aliphatic groups. This is in contrast to the known reactivity patterns of heme enzymes where iron(III)-superoxo and iron(III)-hydroperoxo are sluggish oxidants in aliphatic hydroxylation reactions.

In bleomycin, a glycopeptide antibiotic that digests double-stranded DNA, an iron(III)hydroperoxo intermediate is formed in a reaction with oxygen and iron present in the 
medium. The iron(III)-hydroperoxo can attack the substrate directly or initially converts via either heterogeneous or homogeneous cleavage of the hydroperoxo moiety to form iron(IV)oxo or iron(V)-oxo species. ${ }^{70} 73$ Of these intermediates that catalyze hydrogen abstraction, iron(III)-hydroperoxo and other similar transition metal-peroxo intermediates are the focus of this review and in later sections we will discuss their reactions/catalytic potentials in substrates activation reactions.

\subsection{Short-lived iron-dioxygen complex in CDO enzymes.}

Cysteine catabolism is a vital process for human health and its first step is mediated by a cysteine dioxygenase (CDO). Although cysteine is one of the amino acids that forms building blocks of many proteins in cells, its build-up in neuronal cells is known to be excitotoxic and increased levels of cysteine have been correlated with neurodegenerative diseases. ${ }^{74,75}$ However, it was found that increased activities of CDO result from forced expression of its gene in human cancer cells which is also correlated with decreased tumor cell growths. ${ }^{76}$ As such, the catalytic activities of CDO and its regulation ensure physiological levels of cysteine are maintained constant.

Cysteine dioxygenase catalyzes the conversion of cysteine to cysteine sulfinic acid that is the first irreversible step in cysteine catabolism. ${ }^{77,78}$ The details of the catalytic mechanism of CDO remain incomplete and therefore the mechanism is not yet established. In particular, no experimental data on dioxygen bound intermediates in CDO enzymes were reported, hence all suggestions on short-lived intermediates came from analysis of product distributions and computational modeling. ${ }^{35-39,79}$ Subsequent experimental work and computational studies on biomimetic model complexes gave insight into dioxygen activation and predicted a general mechanism for CDO reaction. ${ }^{39,80,81}$ 
Figure 3 summarizes key intermediates in the catalytic cycle of CDO enzymes. The cycle starts with the resting state complex $(\mathbf{R})$, which is a nonheme iron(II) linked to the protein through three interactions with histidine residues, while the other three ligand positions are occupied by water molecules. The ligand coordination system distinguishes CDO from typical nonheme iron dioxygenases that have the 2-His/1-Asp feature as discussed above. The cycle starts with cysteinate entering the substrate binding pocket and binds the iron(II) complex as a bidentate ligand with the thiolate and amide groups to generate structure $\mathbf{A}$. The last water molecule is expelled from the iron center when dioxygen enters to form the iron(III)-superoxo complex (B). This complex is elusive and has not been trapped and characterized for any nonheme iron dioxygenase. The distal oxygen atom (labeled $\mathrm{O}_{\mathrm{d}}$ ) attacks the thiolate to give a bridging structure $\mathbf{C}$. An $\mathrm{O}-\mathrm{O}$ bond breaking step gives an iron(IV)-oxo species and cysteinesulfoxide intermediate (D) that after the second oxygen atom transfer yields cysteine sulfinic acid products $(\mathbf{E})$. Release of product and rebinding of water returns the active site to the resting state $\mathbf{R}$ and completes the catalytic cycle.

[Figure 3 near here]

UV-Vis absorption studies identified two absorption bands at 500 and $640 \mathrm{~nm}$ for a species containing two oxygen atoms. ${ }^{82}$ Unfortunately, the intermediate decays in $20 \mathrm{~ms}$ and attempts to characterize a short-lived species further, failed, and no indistinguishable EPR and Mössbauer spectra were obtained. Therefore, we resorted to a computational study at the time dependent-density functional theory (TD-DFT) and complete active space - self consistent field (CASSCF) level of theory to establish the nature of the intermediate. In particular, focus was on two reactive intermediates, namely the iron(III)-superoxo anion (B) and iron(III)bicyclic-O-O ring structure (C), but also the cysteine sulfoxide (D) and cysteine sulfinic acid products $(\mathbf{E})$ were considered. 
Evidence from experiments using Mössbauer spectroscopy established the presence of a water-bound structure (with water in the sixth ligand position, i.e. structure $\mathbf{A}$ in Figure 3) of cysteine-bound $\mathrm{CDO}$ but only the cysteine-CDO would go through the dioxygenation reaction under the appropriate conditions. ${ }^{82}$ It was observed that when an anaerobic cysteinebound $\mathrm{CDO}$ was titrated with oxygenated buffer at $4^{\circ} \mathrm{C}$ in a glove-box, this led to the appearance of two absorption peaks at 500 and $640 \mathrm{~nm}$. These peaks were found to scale linearly with concentration of CDO as well as the amount of dioxygen supplied. Since the species with absorption features of 500 and $640 \mathrm{~nm}$ decayed within about $20 \mathrm{~ms}$ it was proposed to be an oxygen adduct in the catalytic cycle of CDO. A first-order rate constant of $112 \pm 5 \mathrm{~s}^{\mathrm{s}^{1}}$ for its decay was measured. The results were further validated with various experimental methods such as chemical quenching and freeze-quench, and thus giving the same outcomes of dioxygenation reactions for anaerobic cysteine-bound CDO. ${ }^{82}$ In addition, computational modeling using density functional theory on model complexes as well as quantum mechanics/molecular mechanics studies on the full enzyme, calculated high reaction barriers for formation of the iron(III)-superoxo and the iron(III)-bicyclic ring species, and, therefore, these calculations predicted a finite lifetime of the two complexes $\mathbf{B}$ and $\mathbf{C}^{35,37}$ On the other hand, formation of the iron-cysteine sulfoxide and iron-cysteine sulfinic acid products is calculated to be strongly exothermic with small barriers of formation and decay. Consequently, the lifetime of these intermediates is expected to be rather short. Figure 4 displays calculated absorption spectra of structures of the iron(III)-superoxo (B), the bicyclic complex (C), the iron-cysteine sulfoxide complex (D) and the iron-cysteine sulfinic acid product complex (E) in the quintet spin state with TD-DFT and CASSCF methods. Although none of the absorption spectra reproduces experiment perfectly, some features are reproduced well. Firstly, as predicted by the DFT and QM/MM calculations of the reaction mechanism, and confirmed with TD-DFT and CASSCF, structures ${ }^{5} \mathbf{D}$ and ${ }^{5} \mathbf{E}$ can be ruled 
out as the intermediates responsible for the absorption features in the experimental spectrum. Either no spectroscopic signal in the correct place is seen, or no signal is seen at all for both intermediates. Secondly, the CASSCF results implicate two clear absorption signals in the $500-700 \mathrm{~nm}$ region for both ${ }^{5} \mathbf{B}$ and ${ }^{5} \mathbf{C}$, whereby the intensity of the peaks for ${ }^{5} \mathbf{C}$ appears to match the experiment the best, although both peaks are shifted with respect to the experimental assignment. Therefore, computational analysis implicated two possible candidates responsible for the experimentally observed absorption maxima, namely ${ }^{5} \mathbf{B}$ or ${ }^{5} \mathbf{C}$. The theory slightly favors the ${ }^{5} \mathbf{C}$ assignment but the error of the calculations is too large for a definitive conclusion. Unfortunately, theory fails to resolve the experimental conundrum and assign the sole species responsible for the absorption spectrum, but the results mostly point to the bicyclic ring structure in the quintet spin state as the species giving the experimental spectra. As such, further analytical work will be necessary to distinguish between the two species; especially using analytic tools that can detect them within a shorter time for instance, at less than $10 \mathrm{~ms}$, in order to assign the role and the nature of the oxygen adduct intermediates in the catalytic cycle of CDO.

[Figure 4 near here]

\subsection{Iron(III)-hydroperoxo in heme and nonheme complexes.}

Early studies on cytochrome P450 mutants that disrupted the proton delivery pathways of $\mathrm{P} 450_{\text {cam }}$, a camphor hydroxylating $\mathrm{P} 450$ isozyme, implicated reactivity patterns of the precursor of CpdI in the catalytic cycle, namely Compound 0 (Cpd0) or the iron(III)hydroperoxo heme complex. ${ }^{60}$ These studies created controversy and suggested that Cpd0 alongside CpdI was catalytically active and could act as a second oxidant in the catalytic cycle of P450. Later density functional theory modeling and quantum mechanics/molecular mechanics studies on double bond epoxidation and sulfide sulfoxidation, ${ }^{55,56,83}$ however, cast 
doubt upon the experimental results and gave sluggish reactivity patterns for Cpd0 as compared to that of CpdI. Further experimental studies of biomimetic model complexes confirmed the conclusions of the theory. ${ }^{59}$

Unlike the heme iron(III)-hydroperoxo that has been shown to be a sluggish oxidant of substrate hydroxylation reactions, a surprising result was found with the hexacoordinated nonheme iron(III)-hydroperoxo counterpart, as in contrast to the heme Cpd0 structure it was proven to be a potent oxidant of, for example, halide transfer and aromatic hydroxylation reactions. ${ }^{61} 63$ This prompted us to perform a detailed computational study of the aromatic hydroxylation of arenes by heme and nonheme iron(III)-hydroperoxo complexes. ${ }^{64,65}$ A detailed computational analysis was performed on an experimentally and spectroscopically characterized pentadentate nonheme iron(III)-hydroperoxo complex namely, $\left[\left(\mathrm{L}_{5}^{2}\right) \mathrm{Fe}^{\mathrm{III}}(\mathrm{OOH})\right]^{2+} \quad$ with $\quad \mathrm{L}_{5}^{2}=\mathrm{N}$-methyl-N,N',N'-tris(2-pyridylmethyl)ethane1,2diamine. ${ }^{62,84}$ The nonheme iron(III)-hydroperoxo model system was carefully characterized with a broad range of spectroscopic methods and was reacted under ideal experimental conditions with benzene and anisole for conversion into phenol products. ${ }^{62}$ However, the studies failed to assign unequivocally the iron(III)-hydroperoxo group as the active oxidant in the reaction mechanism and, therefore, a computational study was needed. Nevertheless, computational studies on the reactivity of the oxidant revealed the intricate details of the aromatic hydroxylation reactions and identified the key intermediate that performs the reactions, see Figure 5. Firstly, the computational studies characterized two stable local reactant structure for the iron(III)-hydroperoxo complex $\left(\operatorname{Re}_{1}\right.$ and $\left.\operatorname{Re}_{2}\right)$ that either have the distal oxygen atom hydrogen bonded to protons of the $\mathrm{L}_{5}^{2}$ ligand or the proximal oxygen atom. These two reactant complexes are within a few $\mathrm{kcal} \mathrm{mol}^{-1}$ of each other and both react with substrates via arene activation. In agreement with experiment, the DFT calculations 
establish the nonheme iron(III)-hydroperoxo complex as a suitable oxidant to activate arenes, such as benzene and anisole, whereby low reaction barriers in solvent were obtained on a doublet spin ground state. $^{64}$ These results highlight nonheme iron(III)-hydroperoxo complexes as potent oxidants of aromatic substrates in contrast to the heme iron(III)hydroperoxo complexes that are sluggish oxidants.

[Figure 5 near here]

As shown in Figure 5, a concerted $\mathrm{OH}$ transfer reaction barrier $\left(\mathbf{T S}_{\mathrm{CO}}\right)$ between $\left[\left(\mathrm{L}_{5}{ }^{2}\right) \mathrm{Fe}^{\mathrm{III}} \mathrm{OOH}\right]^{2+}$ and benzene leads to the formation of an iron(IV)-oxo species and $\mathrm{C}_{6} \mathrm{H}_{6} \mathrm{OH}^{+}$, which after a proton transfer in an almost barrier-less fashion collapses to the phenol products. Also shown are optimized geometries of the rate-determining transition states $\left({ }^{2} \mathbf{T S} \mathbf{C O}_{\text {) }}\right.$ starting from the two isomeric reactants. The two geometric isomers of the complex lead to isomeric transition state structures. Nonetheless, depending on the angle from which the substrate approaches the oxidant, the transition states are either later or earlier on the potential energy surface and have a longer $\mathrm{O}-\mathrm{O}$ bond and a shorter $\mathrm{C}-\mathrm{O}$ bond. Optimized structures of the two transition states are given in Figure 5.

To understand the reactivity differences of heme and nonheme iron(III)-hydroperoxo complexes, we decided to analyze the thermochemical properties of these species and focused initially on the strength of the peroxo bond. In particularly, we investigated the homolytic and heterolytic cleavage of the peroxo moiety of the iron(III)-hydroperoxo complex leading to either an iron(IV)-oxo and an $\mathrm{OH}$ radical or an iron(V)-oxo and an $\mathrm{OH}^{-}$ anion, Figure 6. During the reaction mechanism shown in Figure 5, no intermediates that result from homolytic or heterolytic cleavage of the $\mathrm{O}-\mathrm{O}$ bond were located as local minima. Instead a concerted $\mathrm{OH}$ transfer takes place, so that these intermediates after homolytic or heterolytic breaking are thermodynamically unfeasible reactions. The initial heterolytic 
splitting of the peroxo moiety in $\left[\left(\mathrm{L}_{5}^{2}\right) \mathrm{Fe}^{\mathrm{III}} \mathrm{OOH}\right]^{2+}$ costs $\Delta \mathrm{G}_{\text {solv }}=73.9 \mathrm{kcal} \mathrm{mol}^{-1}$ (Figure 3) and hence is an inaccessible pathway. On the other hand, the initial homolytic splitting of the $\mathrm{O}-\mathrm{O}$ bond of the $\left[\left(\mathrm{L}_{5}^{2}\right) \mathrm{Fe}^{\mathrm{III}} \mathrm{OOH}\right]^{2+}$ complex appears to be thermodynamically feasible with a small endergonicity of $\Delta \mathrm{G}_{\text {solv }}=13.0 \mathrm{kcal} \mathrm{mol}^{-1}$ and hence could be a viable alternative pathway to that shown in Figure 5 above. However, the subsequent reactions between ${ }^{3}\left[\left(\mathrm{~L}_{5}^{2}\right) \mathrm{Fe}^{\mathrm{IV}}(\mathrm{O})\right]^{2+}$ and benzene encounter a reaction barrier of another $24.0 \mathrm{kcal} \mathrm{mol}^{-1}$ on the triplet pathways. ${ }^{85}$ This implies that a total free energy of activation of $\Delta \mathrm{G}_{\text {solv }}=37 \mathrm{kcal} \mathrm{mol}^{-1}$ would be required to initiate the homolytic breakdown of the hydroperoxo group of the $\left[\left(\mathrm{L}_{5}{ }^{2}\right) \mathrm{Fe}{ }^{\mathrm{III}}(\mathrm{OOH})\right]^{2+}$ and the subsequent $\mathrm{C}-\mathrm{O}$ bond formation to the substrate on the triplet pathway. Obviously that pathway is much higher in energy than the concerted pathway displayed in Figure 5 above.

[Figure 6 near here]

Subsequently, we calculated the homolytic and heterolytic cleavage energies of the heme iron(III)-hydroperoxo complex, where we took a small active site model with protoporphyrin IX scaffold (without side chains) and thiolate to mimic the axial cysteinate residue of the iron. ${ }^{86} 90$ The data in Figure 6 show dramatic differences between nonheme and heme iron(III)-hydroperoxo patterns. Thus, in heme iron(III)-hydroperoxo both homolytic and heterolytic $\mathrm{O}-\mathrm{O}$ cleavage patterns require a small amount of energy, i.e. $\Delta \mathrm{G}_{\text {solv }}=10.2 \mathrm{kcal}$ $\mathrm{mol}^{-1}$ for the heterolytic cleavage and $\Delta \mathrm{G}_{\mathrm{solv}}=15.5 \mathrm{kcal} \mathrm{mol}^{-1}$ for homolytic $\mathrm{O}-\mathrm{O}$ bond cleavage. Therefore, heterolytic cleavage and formation of $\mathrm{CpdI}$ is the preferred pathway for 
heme iron(III)-hydroperoxo complexes, whereas homolytic cleavage of the $\mathrm{O}-\mathrm{O}$ bond and formation of a nonheme iron(IV)-oxo complex is preferential in nonheme iron(III)hydroperoxo. Note that the homolytic cleavage pathways are very similar for heme and nonheme iron(III)-hydroperoxo, but major thermodynamic differences are seen for the heterolytic cleavage reactions that are destabilized for the nonheme iron(III)-hydroperoxo species. The reason for this may be the differences in overall charge of the two complexes studied.

The thermodynamic differences between heme and nonheme iron(III)-hydroperoxo, provide the nonheme iron(III)-hydroperoxo system the ability to catalyze direct aromatic hydroxylation reactions of arenes, whereas the heme iron(III)-hydroperoxo intermediate is just a catalytic cycle intermediate en route to CpdI formation. The differences that exist between the two iron(III)-hydroperoxo complexes lies in shape, size and energy levels of the molecular valence orbitals along the metal-peroxo moiety. Orbital analyses have shown that although the valence orbitals of the two systems are characterized by the mixing of metal $3 \mathrm{~d}$ orbitals and the first sphere atoms of the ligand architecture, there are notable orbital interaction differences of the peroxo $(\mathrm{O}-\mathrm{O})$ group and the ligand systems. ${ }^{62}$ Specifically, in heme Cpd0 strong orbital interaction exists between the $\pi_{\mathrm{OO}} *$ orbital in the $x y$-plane and the $a_{2 \mathrm{u}}$ orbital on the porphyrin ligand. Meanwhile this interaction is either lacking or is weaker in the nonheme iron(III)-hydroperoxo system where the $\pi_{\mathrm{OO}} *$ orbital can only interact with nitrogen atoms in the equatorial plane of the ligand system. As a consequence, the nonheme $\pi_{\mathrm{OO}}{ }^{*}$ orbital becomes the highest occupied molecular orbital (HOMO) rather than a ligand orbital. This implies that the ligand cannot be oxidized in the reaction. By contrast, in P450 Cpd0 the $\pi_{\mathrm{OO}} *$ orbital mixes with the ligand $a_{2 \mathrm{u}}$ orbital and becomes the HOMO orbital which would make it susceptible to heterolytic cleavage to form Cpd I and a hydroxide anion. 


\subsection{Spin-state reactivity in biomimetic manganese(V)-oxo complexes.}

Several enzymes and proteins in Nature utilize manganese in their active center rather than iron with examples ranging from superoxide dismutase ${ }^{91,92}$ and Photosystem II. The latter contains a cubane-type cluster with four manganese, a calcium and five oxygen atoms for the biosynthesis of molecular oxygen. ${ }^{93}$ As such, understanding how oxygen atoms or molecules bind to manganese centers is important and will give insight into the mechanism of these important enzymes in nature. In the next two sections we will cover biomimetic studies on two manganese complexes and their reactivity patterns.

Manganese(V)-oxo porphyrinoid complexes are well studied particularly with corrole and corrolazine ligand systems as they have a total charge of -2 and hence can stabilize metals in high oxidation states easily. ${ }^{94,95}$ In particular, in collaboration with the Goldberg group we investigated the structure and reactivity of a manganese(V)-oxo corrolazine complex $\left[\mathrm{Mn}(\mathrm{O})\left(\mathrm{H}_{8} \mathrm{Cz}\right) \mathrm{X}\right], \mathrm{H}_{8} \mathrm{Cz}$ is corrolazine without side chains and $\mathrm{X}$ is the axial ligand $(\mathrm{X}=$ no ligand or $\left.\mathrm{CN}^{-} / \mathrm{F}^{-}\right)$. We initially investigated the axial ligand effect on the dehydrogenation of 9,10-dihydroanthracene and showed that the reaction rate was enhanced by a factor of 2100 upon the addition of $\mathrm{F}^{-}$, while it increased by a factor of 16000 with addition of $\mathrm{CN}^{-} .{ }^{96,97}$ Similar rate enhancements were seen for the use of 1,4-cyclohexadiene as a substrate. It was established that the main cause of the rate enhancement was increased acidity of the manganese(IV)-hydroxo product, which is formed as a result of strong electron-donating properties of the axial ligand. These initial studies only considered the closed-shell singlet spin ground state as it is known to be the ground state for the $\left[\mathrm{Mn}(\mathrm{O})\left(\mathrm{H}_{8} \mathrm{Cz}\right)\right]$ complex. Shaik and co-workers, however, contrasted these studies and proposed an alternative hypothesis 
where the reactant has close-lying singlet and triplet spin states and a spin state crossing to a higher spin state and thereby would lower the reaction rate. ${ }^{98}$

Figure 7 shows high-lying occupied and low-lying virtual orbitals of the $\left[\mathrm{Mn}(\mathrm{O})\left(\mathrm{H}_{8} \mathrm{Cz}\right)(\mathrm{CN})\right]^{-}$complex. Thus, the molecular orbitals depend on the manganese-oxo interactions and those on the corrolazine scaffold. The lowest pair of orbitals shown in Figure 7 is the bonding combination of the $2 \mathrm{p}_{\mathrm{x}} / 2 \mathrm{p}_{\mathrm{y}}$ atomic orbitals on oxygen with the $3 \mathrm{~d}_{\mathrm{xz}} / 3 \mathrm{~d}_{\mathrm{yz}}$ atomic orbitals on manganese: $\pi_{\mathrm{xz}} / \pi_{\mathrm{yz}}$. A little higher in energy is the non-bonding orbital $\delta_{\mathrm{xy}}$ that is located in the plane of the corrolazine ligand midway in between the nitrogen atoms. Above the $\delta_{\mathrm{xy}}$ orbital are the pair of anti-bonding orbitals $\pi^{*}{ }_{\mathrm{xz}} / \pi^{*}{ }_{\mathrm{yz}}$ and two virtual $\sigma^{*}$ orbitals for the interaction between the metal and corrolazine nitrogen atoms $\left(\sigma^{*} x_{2-y}\right)$ and between the metal and oxo group $\left(\sigma^{*}{ }_{z 2}\right)$. A final orbital shown in Figure 7 is the corrolazine $\pi$-orbital labeled as $a^{\prime \prime}$, which shows resemblance to the $a_{1 \mathrm{u}}$ orbital in porphyrins. In the closed-shell singlet ground state of the $\left[\mathrm{Mn}(\mathrm{O})\left(\mathrm{H}_{8} \mathrm{Cz}\right)\right]$ complex the orbital occupation is [core] $\pi_{\mathrm{xz}}{ }^{2} \pi_{\mathrm{yz}}{ }^{2} \mathrm{a}^{\prime \prime 2} \delta_{\mathrm{xy}}{ }^{2}$. This orbital occupation corresponds to a short Mn-O distance and hence creates a triple bond between manganese and oxygen. Higher in energy is a triplet spin state with [core] $\pi_{\mathrm{xz}}{ }^{2} \pi_{\mathrm{yz}}{ }^{2} a^{\prime \prime 1} \delta_{\mathrm{xy}}{ }^{1} \pi^{*}{ }_{\mathrm{xz}}{ }^{1} \pi_{\mathrm{yz}}^{*}{ }^{1}$ configuration, which becomes accessible upon binding of, for instance, $\mathrm{Zn}^{2+}$ anions to the complex through a valence tautomerism mechanism. ${ }^{99}$ In addition, there are two more possible triplet spin states with occupation [core] $\pi_{\mathrm{xz}}{ }^{2} \pi_{\mathrm{yz}}{ }^{2} \mathrm{a}^{\prime \prime 2} \delta_{\mathrm{xy}}{ }^{1} \pi^{*}{ }_{\mathrm{xz}}{ }^{1} \pi^{*}{ }_{\mathrm{yz}}{ }^{0}$ and [core] $\pi_{\mathrm{xz}}{ }^{2} \pi_{\mathrm{yz}}{ }^{1} \mathrm{a}^{\prime \prime 2} \delta_{\mathrm{xy}}{ }^{1} \pi^{*}{ }_{\mathrm{xz}}{ }^{1} \pi^{*}{ }_{\mathrm{yz}}{ }^{1}$.

[Figure 7 near here]

As the spin state ordering of $\left[\mathrm{Mn}(\mathrm{O})\left(\mathrm{H}_{8} \mathrm{Cz}\right)(\mathrm{CN})\right]^{-}$was controversial, experimental studies focused on its spectroscopic characterization, and X-ray absorption spectroscopy characterized the structure with a short $\mathrm{Mn}-\mathrm{O}$ bond length typical for a closed-shell singlet 
spin state. ${ }^{100}$ Hence, if a triplet spin state is involved in the reaction mechanism then a spin state crossing from the closed-shell singlet spin state to one of the possible triplet spin states must happen along the reaction mechanism for substrate activation and ideally before the rate determining reaction barrier. To this end, we investigated thioanisole sulfoxidation by $\left[\mathrm{Mn}(\mathrm{O})\left(\mathrm{H}_{8} \mathrm{Cz}\right)(\mathrm{CN})\right]^{-}$with substrates with a range of para-substituents and measured and calculated rate constants for the reaction. ${ }^{101}$ The studies gave a V-shaped Hammett plot characteristic for a change in mechanism during the reaction; however, as the trends were not fully understood a computational study was subsequently performed. ${ }^{102}$

[Figure 8 near here]

For a large set of para-X-substituted thioanisole substrates $\left(\mathrm{X}=\mathrm{N}\left(\mathrm{CH}_{3}\right)_{2}, \mathrm{NH}_{2}, \mathrm{OCH}_{3}, \mathrm{CH}_{3}\right.$, $\mathrm{H}, \mathrm{Br}, \mathrm{CN}$ and $\left.\mathrm{NO}_{2}\right)$ the sulfoxidation mechanism by $\left[\mathrm{Mn}(\mathrm{O})\left(\mathrm{H}_{8} \mathrm{Cz}\right)(\mathrm{CN})\right]^{-}$was calculated with density functional theory methods. ${ }^{102}$ Subsequently, the free energy of activation was converted into a rate enhancement $\left(\log \mathrm{k}_{\mathrm{X}} / \mathrm{k}_{\mathrm{H}}\right)$ of the free energy of activation for para-Xthioanisole relative to para-H-thioanisole and the results of the singlet and triplet spin barriers are given in Figure 8. As can be seen, in agreement with the experimental observation, the singlet spin plot gives a V-shaped Hammett plot, whereas the plot is linear for the triplet spin state of data. To confirm that no spin state crossing from the singlet to the triplet spin state is possible, we also calculated minimum energy crossing point (MECP) structures, but firstly they were high in energy (of the same level as the sulfoxidation transition states) and secondly were not lying on the pathway for sulfoxidation. Moreover, calculations of the spin orbit coupling constant gave very small values, which implicate little (if at all) spin state crossing from singlet to triplet. Consequently, the computational modeling reveals a spin selective reactivity of $\left[\mathrm{Mn}(\mathrm{O})\left(\mathrm{H}_{8} \mathrm{Cz}\right)(\mathrm{CN})\right]^{-}$with thioanisoles and a dominant spin state 
surface only. As such, as a high spin state is not essential for chemical reactivity, and reactions can take place on a closed-shell singlet spin state surface.

It should be mentioned here that a recent benchmark study on the substrate activation of paraX-substituted thioanisole sulfoxidation $\left(\mathrm{X}=\mathrm{H}, \mathrm{CH}_{3}, \mathrm{OCH}_{3}, \mathrm{Cl}\right)$ by $[\mathrm{Fe}(\mathrm{O})(\mathrm{N} 4 \mathrm{Py})]^{2+}, \mathrm{N} 4 \mathrm{Py}=$ $\mathrm{N}, \mathrm{N}$-bis(2-pyridylmethyl)-N-bis(2-pyridyl) methylamine, with a range of density functional theory methods showed that computation reproduces Hammett trends with almost all methods, but often gives a systematic error from the experimental enthalpy of activation. ${ }^{103} \mathrm{~A}$ parallel outcome was found for regioselectivity patterns of bifurcation pathways. ${ }^{104,105}$

\subsection{Aldehyde deformylation by manganese(III)-peroxo complexes.}

Another interesting chemistry property of a metal-peroxo system is exemplified in the reaction of a manganese(III)-peroxo complex with 2-phenylpropionaldehyde (2-PPA). ${ }^{106}$ Manganese-containing enzymes are common in nature and their reactions show similarity to those of the iron enzymes. In particular, in a reaction with molecular oxygen, catalytic intermediates are formed that include side-on manganese(III)-peroxo, end-on manganese(IV)-superoxo and the above mentioned manganese(V)-oxo species. Generally, these intermediates are short-lived and unfortunately little experimental evidence of enzymatic side-on manganese(III)-peroxo species exists. They are thought to be important intermediates in the catalytic cycles of biological systems such as photosystem II and superoxide dismutase. ${ }^{91 \_93}$ The latter catalyzes the photolysis of water to generate molecular oxygen and the former is involved in the biodegradation of toxic superoxide to hydrogen peroxide and water, respectively. As such, inspired by these natural phenomena of reactions mediated by manganese centers, synthetic biomimetic models have been developed to understand the catalytic intermediates of these important enzymes and proteins. 
Previous reactivity studies of heme and nonheme metal-peroxo complexes with aldehydes concluded that the reaction takes place with a rate-determining nucleophilic attack on the carbonyl group of the aldehyde. ${ }^{107} 109$ In order to explore further the catalytic ability of manganese-peroxo intermediates with aldehydes, an experimental and computational study was carried-out for a side-on manganese(III)-peroxo complex with a bispidine ligand system. The work was initiated with a computational study and the mechanism is displayed in Figure 9. Thus, two alternative mechanisms were considered namely, a hydrogen atom abstraction from the $\alpha$-carbon of the aldehyde substrate and a nucleophilic attack on the carbonyl group of the substrate. ${ }^{106}$ Interestingly, the nucleophilic attack undergoes a high-energy barrier of $\Delta \mathrm{E}^{\ddagger}=28.7 \mathrm{kcal} \mathrm{mol}{ }^{-1}$, whereas the hydrogen atom abstraction barrier was found to be considerably lower: $23.9 \mathrm{kcal} \mathrm{mol}^{-1}$. It appears, therefore, that the aldehyde deformylation reaction is initiated with a rate-determining hydrogen atom abstraction.

Experimental studies to support the computational mechanistic proposal were performed and established a kinetic isotope effect (KIE) of about 5 for the ratio of the rate constants between 2-phenyl propionaldehyde versus $2-\mathrm{d}_{1}$-2-phenyl propionaldehyde. These studies implicate a rate determining hydrogen atom abstraction for aldehyde deformylation in agreement with the density functional theory studies. Subsequent work using 2-methyl-2-phenylpropionaldehyde as a substrate yielded no products and hence gave further evidence of a ratedetermining hydrogen atom abstraction.

[Figure 9 near here]

The question is why does the side-on manganese(III)-peroxo complex prefer to react through a hydrogen atom abstraction rather than the reported nucleophilic attack on the carbonyl carbon? The reason for this originates from the redox potential of the oxidant. Thus, the sideon manganese(III)-peroxo has a low redox potential and can efficiently abstract an electron 
from the peroxo moiety. By contrast, the electron transfer to the carbonyl group of the substrate by the peroxo group would lead to the nucleophilic pathway, but is much higher in energy. To understand these differences in electron transfer properties, a valence bond/molecular orbital analysis on the reactants, intermediates and products was carried out, and this is schematically depicted in Figures $10-12$.

[Figure 10 near here]

[Figure 11 near here]

[Figure 12 near here]

The top part of Figure 10 shows the electron transfer and bond breaking/forming processes during the hydrogen atom abstraction reaction. Each dot in the Figure represents one electron and a line with two dots is a bonding orbital with two electrons. Only key orbitals are shown in this Figure. Thus, the manganese(III)-peroxo complex has an electronic configuration with four singly occupied orbitals on the manganese in quintet spin state: $3 \mathrm{~d}_{\mathrm{xz}}{ }^{1} 3 \mathrm{~d}_{\mathrm{xy}}{ }^{1} \sigma^{*}{ }_{\mathrm{x} 2-\mathrm{y} 2}{ }^{1} \sigma^{*}{ }_{\mathrm{z} 2}{ }^{1}$. In addition, there are two relevant orbitals on the peroxo moiety, namely $\pi_{\mathrm{OO} \text {,xy }}$ and $\pi^{*} \mathrm{OO}$,xy both occupied with two electrons. In the hydrogen atom abstraction step, the $\sigma_{\mathrm{CH}}$ orbital for the interaction of the $\mathrm{C}$ and $\mathrm{H}$ atoms breaks into atomic orbitals: $2 \mathrm{p}_{\mathrm{C}}$ and $1 \mathrm{~s}_{\mathrm{H}}$. Next, the $\pi_{\mathrm{OO}, \mathrm{xy}}$ and $\pi^{*}{ }_{\mathrm{OO}, \mathrm{xy}}$ convert back to atomic orbitals and one electron pairs up with the $1 \mathrm{~s}_{\mathrm{H}}$ atomic orbital to form the new $\sigma_{\mathrm{OH}}$ bond. Two electrons originating from the $\pi_{\mathrm{OO} \text {,xy }} / \pi^{*}{ }_{\mathrm{OO} \text {,xy }}$ orbitals pair up with the manganese $3 d_{x z}$ electron to form a new manganese-oxo three-electron bond: $\pi_{\mathrm{xz}}{ }^{2} \pi_{\mathrm{xz}}^{*}$. The last electron from the peroxo bond is promoted to the $3 \mathrm{~d}_{\mathrm{yz}}$ orbital of manganese. Therefore, the hydrogen atom abstraction barrier will be determined by the energy to break the $\mathrm{C}-\mathrm{H}$ bond of the substrate $\left(\sigma_{\mathrm{CH}}\right)$, the energy to form the $\mathrm{O}-\mathrm{H}$ bond in the product $\left(\sigma_{\mathrm{OH}}\right)$, the energy to break the $\pi$-bond of the peroxo group $\left(\pi_{\mathrm{OO}, \mathrm{xy}} / \pi^{*}{ }_{\mathrm{OO}, \mathrm{xy}}\right)$ and finally the energy to excite an electron from the peroxo to the $3 d_{\mathrm{yz}}$ orbital on manganese. 
The contrasting nucleophilic addition pathway is shown at the bottom of Figure 10. Similarly to the hydrogen atom abstraction step, the $\pi_{\mathrm{OO}, \mathrm{xy}}$ and $\pi^{*}$ oO,xy revert to atomic orbitals and an end-on peroxo is formed with a new set of $\pi_{\mathrm{xz}} / \pi^{*}{ }_{\mathrm{xz}}$ orbitals along the manganese-oxo group. However, no electron transfer into the manganese takes place but instead the electron is donated into the carbonyl group of the substrate. In particular, the $\pi$-bond of the carbonyl $\left(\pi_{\mathrm{CO}}\right)$ breaks into atomic orbitals $\left(2 \mathrm{p}_{\mathrm{C}}\right.$ and $\left.2 \mathrm{p}_{\mathrm{O}}\right)$, whereby the $2 \mathrm{p}_{\mathrm{O}}$ orbital receives a second electron from the peroxo group and the $2 \mathrm{p}_{\mathrm{C}}$ forms a covalent bond $\left(\sigma_{\mathrm{O} 2-\mathrm{C}}\right)$ with the peroxo moiety. Therefore, the relative electron affinity of the substrate carbonyl versus the manganese atom will determine whether the dominant pathway is hydrogen atom abstraction or nucleophilic addition.

To further explain and rationalize the bifurcation pathways and make predictive measurements on how the regioselectivity can be changed, we designed a valence bond/molecular orbital scheme to understand the details of the reaction mechanisms. These valence bond curve crossing diagrams were initially developed by Shaik, ${ }^{110}$ and, for instance, show predicted hydrogen atom abstraction barriers for cytochrome P450 Compound I. ${ }^{11}$ Recently we designed a different model based on the crossing of two parabolas. ${ }^{112}$ Thus, in the two-parabola curve crossing description the potential energy curve $(y)$ is described as a parabola with the minimum energy point for the reactants located at reaction coordinate $x_{\mathrm{R}}=$ 0 , i.e. $y_{\mathrm{R}}=a x^{2}$ with $a$ a constant. The product geometry is located at the minimum of a parabola at reaction coordinate $x_{\mathrm{P}}=1$ and energy function $y_{\mathrm{P}}=b x^{2}+c x+d$ where $b, c$ and $d$ are constants. We now assume that the transition state is located at a reaction coordinate $x=$ $1 / 2$ at the point where the two curves cross. Shaik showed that the curve crossing energy is correlated with a fraction of the excitation energy between the curves in the reactant geometry. ${ }^{110}$ Similarly, from the crossing point of the two parabolic functions we can derive that it is related to the values of $y_{\mathrm{P}}(0)$ and $y_{\mathrm{P}}(1)$, which represent the Franck-Condon energy in 
the reactant complex $\left(\mathrm{E}_{\mathrm{FC}, \mathbf{R}}\right)$ and the driving force for the reaction $\left(\Delta \mathrm{E}_{\mathrm{rp}}\right)$, respectively. ${ }^{112}$ As with the VB, the reaction barrier can be estimated by subtracting the resonance energy from the curve crossing energy.

By analyzing the electronic configurations of the ground and excited state complexes in the geometry of the reactants, it can be reasoned that the value $\mathrm{E}_{\mathrm{FC}, \mathbf{R}}$ for hydrogen atom abstraction is dependent on the energy to break the $\mathrm{C}-\mathrm{H}$ bond of the substrate, the energy to form the $\mathrm{O}-\mathrm{H}$ bond between peroxo and incoming hydrogen atom, the breaking of the $\pi_{\mathrm{OO}}$ bond of the peroxo group, the formation energy of the three-electron $\pi_{\mathrm{MnO}} / \pi^{*} \mathrm{MnO}$ bond and the energy to transfer an electron from peroxo to manganese. We estimated values for each of these contributions from the molecular orbital energies of the reactant complex and the adiabatic $\mathrm{C}-\mathrm{H}$ and $\mathrm{O}-\mathrm{H}$ bond energies, which gave a predicted hydrogen atom abstraction barrier of $31.7 \mathrm{kcal} \mathrm{mol}^{-1}$. This value matches the DFT calculated hydrogen atom abstraction barrier well.

Subsequently, we predicted the nucleophilic attack barrier in a similar way. In the nucleophilic pathway, the $\pi$-bond of the substrate carbonyl bond is broken. In addition, the $\pi_{\mathrm{OO}}$ bond of the peroxo moiety is broken and a three-electron $\mathrm{MnO}$ bond is formed, similarly to that seen in the hydrogen atom abstraction process. Finally, in the nucleophilic addition transition state a $\mathrm{C}-\mathrm{O}$ bond is formed between carbonyl and peroxo group and an electron is transferred from peroxo to the carbonyl oxygen atom. Based on orbital energies, we estimate a nucleophilic addition barrier of $33.2 \mathrm{kcal} \mathrm{mol}^{-1}$, in good agreement with the DFT calculations.

In summary, the bispidine-ligated manganese(III)-peroxo complex reacts with aldehydes via hydrogen atom abstraction rather than a nucleophilic attack on the carbonyl group. A detailed rationalization of the orbital changes in the reaction pathways reveals that the difference between the two pathways is mostly related to the electron transfer from the peroxo species. 
Thus, in hydrogen atom abstraction, the peroxo group donates an electron to the manganese, whereas in the nucleophilic pathway the electron transfers to the substrate carbonyl group instead. The selectivity of hydrogen atom abstraction versus nucleophilic addition, therefore, is determined by the relative electron affinity of the manganese with respect to the substrate carbonyl group. In our system, the manganese is a sufficiently effective electrophile and can abstract electrons easily and much better than the substrate carbonyl group. This may in part be due to steric repulsions on substrate approach.

\section{Conclusions}

As highlighted by several examples in this work, metal-oxo, metal-peroxo and metalhydroperoxo moieties show unique reactivity patterns with substrates. Often these metal complexes have close lying spin and electronic states and the crossing-over from one surface to the other affects the reactivity patterns with substrates. Computational modeling has given insight into the nature of metal-oxo, metal-peroxo and metal-hydroperoxo complexes. Some of these complexes are intermediates in the catalytic cycles of heme and nonheme iron enzymes, but not all of these are reactive with substrates. Our on-going work elucidates structure and reactivity and predicts trends.

\section{Acknowledgements}

ASF thanks the Tertiary Education Trust Fund Nigeria for a studentship. The Inorganic Reaction Mechanisms Discussion group of the Dalton Division of the Royal Society of Chemistry is thanked for support.

\section{References}

1. Solomon, E. I.; Brunold, T. C.; Davis, M. I.; Kemsley, J. N.; Lee, S.-K.; Lehnert, N.; Neese, F.; Skulan, A. J.; Yang, Y.-S.; Zhou, J. Chem. Rev. 2000, 100, 235-349. 
2. Bugg, T. D. H. Curr. Opin. Chem. Biol. 2001, 5, 550-555.

3. Ryle, M. J.; Hausinger, R. P. Curr. Opin. Chem. Biol. 2002, 6, 193-201.

4. Costas, M.; Mehn, M. P.; Jensen, M. P.; Que Jr, L. Chem. Rev. 2004, 104, 939-986.

5. Abu-Omar, M. M.; Loaiza, A.; Hontzeas, N. Chem. Rev. 2005, 105, 2227-2252.

6. de Visser, S. P.; Kumar, D., Eds., Iron-containing enzymes: Versatile Catalysts of Hydroxylation Reaction in Nature, RSC Publishing, Cambridge (UK), 2011.

7. Bruijnincx, P. C.; van Koten, G.; Klein Gebbink, R. J. Chem. Soc. Rev. 2008, 37, 2716-2744.

8. Sono, M.; Roach, M. P.; Coulter, E. D.; Dawson, J. H. Chem. Rev. 1996, 96, 2841-2888.

9. Ortiz de Montellano, P. R., Ed., Cytochrome P450: Structure, Mechanism and Biochemistry, $3^{\text {rd }}$ ed., Kluwer Academic/Plenum Publishers, New York, 2005.

10. Meunier, B.; de Visser, S. P.; Shaik, S. Chem. Rev. 2004, 104, 3947-3980.

11. Denisov, I. G.; Makris, T. M.; Sligar, S. G.; Schlichting, I. Chem. Rev. 2005, 105, 2253-2277.

12. Watanabe, Y.; Nakajima, H.; Ueno, T. Acc. Chem. Res. 2007, 40, 554-562.

13. Krebs, C.; Galonic Fujimori, D.; Walsh, C. T.; Bollinger Jr, J. M. Acc. Chem. Res. 2007, 40, 484-492.

14. Hausinger, R. P. Crit. Rev. Biochem. Mol. Biol. 2004, 39, 21-68.

15. Hernández-Ortega, A.; Quesne, M. G.; Bui, S.; Heuts, D. P. H. M.; Steiner, R. A.; Heyes, D. J.; de Visser, S. P.; Scrutton, N. S. J. Biol. Chem. 2014, 289, 8620-8632.

16. Hernández-Ortega, A.; Quesne, M. G.; Bui, S.; Heyes, D. J.; Steiner, R. A.; Scrutton, N. S.; de Visser, S. P. J. Am. Chem. Soc. 2015, 137, 7474-7487.

17. Solomon, E. I.; Decker, A.; Lehnert, N. Proc. Natl. Acad. Sc. USA 2003, 100, 3589-3594.

18. de Visser, S. P. Coord. Chem. Rev. 2009, 253, 754-768.

19. O'Brien, J. R.; Schuller, D. J.; Yang, V. S; Dillard, B. D.; Lanzilotta, W. N. Biochemistry, 2003, 42, $5547-5554$.

20. Bollinger Jr, J. M.; Price, J. C.; Hoffart, L. M.; Barr, E. W.; Krebs, C. Eur. J. Inorg. Chem. 2005, $4245-4254$. 
21. Borowski, T.; Bassan, A.; Siegbahn, P. E. M. Chem. Eur. J. 2004, 10, 1031-1041.

22. de Visser, S. P. Chem. Commun. 2007, 171-173.

23. Godfrey, E.; Porro, C. S.; de Visser, S. P. J. Phys. Chem. A 2008, 112, 2464-2468.

24. Quesne, M. G.; Latifi, R.; Gonzalez-Ovalle, L. E.; Kumar, D.; de Visser, S. P. Chem. Eur. J. 2014, 20, 435-446.

25. de Visser, S. P. Angew. Chem. Int. Ed. 2006, 45, 1790-1793.

26. de Visser, S. P. J. Am. Chem. Soc. 2006, 128, 9813-9824.

27. Latifi, R.; Bagherzadeh, M.; de Visser, S. P. Chem. Eur. J. 2009, 15, 6651-6662.

28. de Visser, S. P. J. Am. Chem. Soc. 2010, 132, 1087-1097.

29. Karamzadeh, B.; Kumar, D.; Sastry, G. N.; de Visser, S. P. J. Phys. Chem. A 2010, 114, 13234 13243.

30. Pratter, S. M.; Konstantinovics, C.; DiGiuro, C. L. M.; Leitner, E.; Kumar, D.; de Visser, S. P.; Grogan, G.; Straganz, G. D. Angew. Chem. Int. Ed. 2013, 52, 9677-9681.

31. Straganz, G. D.; Nidetzky, B. ChemBioChem. 2006, 7, 1536-1548.

32. Joseph, C. A.; Maroney, M. J. Chem. Commun. 2007, 32, 3338-3349.

33. Goncharenko, K. V.; Vit, A.; Blankenfeldt, W.; Seebeck, F. P. Angew. Chem. Int. Ed. 2015, 54, 28212824.

34. Goncharenko, K. V.; Seebeck, F. P. Chem. Commun. 2016, 52, 1945-1948.

35. Aluri, S.; de Visser, S. P. J. Am. Chem. Soc. 2007, 129, 14846-14847.

36. de Visser, S. P.; Straganz, G. D. J. Phys. Chem. A 2009, 113, 1835-1846.

37. Kumar, D.; Thiel, W.; de Visser, S. P. J. Am. Chem. Soc. 2011, 133, 3869-3882.

38. Kumar, D.; Sastry, G. N.; Goldberg, D. P.; de Visser, S. P. J. Phys. Chem. A 2012, 116, 582-591.

39. Sallmann, M.; Kumar, S.; Chernev, P.; Nehrkorn, J.; Schnegg, A.; Kumar, D.; Dau, H.; Limberg, C.; de Visser, S. P. Chem. Eur. J. 2015, 21, 7470-7479.

40. Ortiz de Montellano, P. R. Chem. Rev. 2010, 110, 932-967.

41. Costas, M. Coord. Chem. Rev. 2011, 255, 2912-2932.

42. de Visser, S. P. Adv. Inorg. Chem. 2012, 64, 1-31. 
43. de Visser, S. P.; Nam, W. "High-valent iron-oxo porphyrins in oxygenation reactions." In Handbook of Porphyrin Science, Kadish, K. M.; Smith, K. M.; Guilard, R. (Eds.); World Scientific Publishing Co., New Jersey, 2010, Chapter 44, pp. 85-140.

44. de Visser, S. P.; Ogliaro, F.; Sharma, P. K.; Shaik, S. Angew. Chem. Int. Ed. 2002, 41, 1947-1951.

45. de Visser, S. P.; Ogliaro, F.; Sharma, P. K.; Shaik, S. J. Am. Chem. Soc. 2002, 124, 11809-11826.

46. de Visser, S. P.; Kumar, D.; Neumann, R.; Shaik, S. Angew. Chem. Int. Ed. 2004, 43, 5661-5665.

47. Kumar, D.; de Visser, S. P.; Sharma, P. K.; Derat, D.; Shaik, S. J. Biol. Inorg. Chem. 2005, 10, 181189.

48. de Visser, S. P. J. Biol. Inorg. Chem. 2006, 11, 168-178.

49. Wang, R.; de Visser, S. P. J. Inorg. Biochem. 2007, 101, 1464-1472.

50. de Visser, S. P.; Shaik, S.; Sharma, P. K.; Kumar, D.; Thiel, W. J. Am. Chem. Soc. 2003, 125, 1577915788.

51. Rittle, J.; Green, M. T. Science 2010, 330, 933-937.

52. Cryle, M. J.; De Voss, J. J. Angew. Chem. Int. Ed. Engl. 2006, 45, 8221-8223.

53. Fertinger, C.; Hessenauer-Ilicheva, N.; Franke, A.; van Eldik, R. Chem. Eur. J. 2009, 15, 1343513440.

54. Franke, A.; Wolak, M.; van Eldik, R. Chem. Eur. J. 2009, 15, 10182-10198.

55. Ogliaro, F.; de Visser, S. P.; Cohen, S.; Sharma, P. K.; Shaik, S. J. Am. Chem. Soc. 2002, 124, 28062817.

56. Kamachi, T.; Shiota, Y.; Ohta, T.; Yoshizawa, K. Bull. Chem. Soc. Jpn. 2003, 76, 721-732.

57. Kitagishi, H.; Tamaki, M.; Ueda, T.; Hirota, S.; Ohta, T.; Naruta, Y.; Kano, K. J. Am. Chem. Soc. 2010, 132, 16730-16732.

58. Ohta, T.; Liu, J.-G.; Naruta, Y. Coord. Chem. Rev. 2013, 257, 407-413.

59. Park, M. J.; Lee, J.; Suh, Y.; Kim, J.; Nam, W. J. Am. Chem. Soc. 2006, 128, 2630-2634.

60. Vaz, A. D.; McGinnity, D. F.; Coon, M. J. Proc. Natl. Acad. Sci. USA 1998, 95, 3555-3560.

61. Vardhaman, A. K.; Sastri, C. V.; Kumar, D.; de Visser, S. P. Chem. Commun. 2011, 47, 11044 11046. 
62. Thibon, A.; Jollet, V.; Ribal, C.; Sénéchal-David, K.; Billon, L.; Sorokin, A. B.; Banse, F. Chem. Eur. J. 2012, 18, 2715-2724.

63. Vardhaman, A. K.; Barman, P.; Kumar, S.; Sastri, C. V.; Kumar, D.; de Visser, S. P. Chem. Commun. 2013, 49, 10926-10928.

64. Faponle, A. S.; Quesne, M. G.; Sastri, C. V.; Banse, F.; de Visser, S. P. Chem. Eur. J. 2015, 21, 12211236.

65. Faponle, A. S.; Banse, F.; de Visser, S. P. J. Biol. Inorg. Chem. 2016, 21, 453-462.

66. Kryatov, S. V.; Rybak-Akimova, E. V.; Schindler, S. Chem. Rev. 2005, 105, 2175-2226.

67. Stipanuk, M. H. Annu. Rev. Nutr. 2004, 24, 539-577.

68. Baldwin, J. E.; Bradley, M. Chem. Rev. 1990, 90, 1079-1088.

69. Lundberg, M.; Siegbahn, P. E. M.; Morokuma, K. Biochemistry 2008, 47, 1031-1042.

70. Kumar, D.; Hirao, H.; Shaik, S.; Kozlowski, P. M. J. Am. Chem. Soc. 2006, 128, 16148-16158.

71. Liu, L. V.; Bell III, C. B.; Wong, S. D.; Wilson, S. A.; Kwak, Y.; Chow, M. S.; Zhao, J.; Hodgson, K. O.; Hedman, B.; Solomon, E. I. Proc. Natl. Acad. Sci. USA 2010, 107, 22419-22424.

72. Stubbe, J.; Kozarich, J. W.; Wu, W.; Vanderwall, D. E. Acc. Chem. Res. 1996, 29, 322-330.

73. Burger, R. M. Chem. Rev. 1998, 98, 1153-1170.

74. Heafield, M. T.; Fearn, S.; Steventon, G. B.; Waring, R. H.; Williams, A. C.; Sturman, S. G. Neurosci. Lett., 1990, 110, 216-224.

75. Perry, T. L.; Norman, M. G.; Yong, V. W.;Whiting, S.; Crichton, J. U.; Hansen, S.; Kish, S. J. Ann. Neurol. 1985, 18, 482-495.

76. Brait, M; Ling, S.; Nagpal, J. K.; Chang, X.; Park, H. L.; Lee, J.; Okamura, J.; Yamashita, K.; Sidransky, D.; Kim, M. S. PLoS One, 2012, 7, e44951.

77. Stipanuk, M. H.; Simmons, C. R.; Karplus, P. A.; Dominy, Jr., J. E. Amino Acids 2010, 41, 91-112.

78. Stipanuk, M. H.; Ueki, I. J. Inherited Metab. Dis. 2010, 34, 17-34. 
79. Gonzalez-Ovalle, L. E.; Quesne, M. G.; Kumar, D.; Goldberg, D. P.; de Visser, S. P. Org. Biomol. Chem. 2012, 10, 5401-5409.

80. McQuilken, A. C.; Goldberg, D. P. Dalton Trans. 2012, 41, 10883-10899.

81. Widger, L. R.; Davies, C. G.; Yang, T.; Siegler, M. A.; Troeppner, O.; Jameson, G. N. L.; IvanovicBurmazovic, I.; Goldberg, D. P. J. Am. Chem. Soc. 2014, 136, 2699-2701.

82. Tchesnokov, E. P.; Faponle, A. S.; Davies, C. G.; Quesne, M. G.; Turner, R.; Fellner, M.; Souness, R. J.; Wilbanks, S. M.; de Visser, S. P.; Jameson G. N. L. Chem. Commun. 2016, 52, 8814-8817.

83. Porro, C. S.; Sutcliffe, M. J.; de Visser, S. P. J. Phys. Chem. A 2009, 113, 11635-11642.

84. Thibon, A.; Bartoli, J.-F.; Guillot, R.; Sainton, J.; Martinho, M.; Mansuy, D.; Banse, F. J. Mol. Catal. A 2008, 287, 115-120.

85. de Visser, S. P.; Oh, K.; Han, A.-R.; Nam, W. Inorg. Chem. 2007, 46, 4632-4641.

86. de Visser, S. P.; Tan, L. S. J. Am. Chem. Soc. 2008, 130, 12961-12974.

87. Sainna, M. A.; Kumar, S.; Kumar, D.; Fornarini, S.; Crestoni, M. E.; de Visser, S. P. Chem. Sci. 2015, $6,1516-1529$.

88. Ji, L.; Faponle, A. S.; Quesne, M. G.; Sainna, M. A.; Zhang, J.; Franke, A.; Kumar, D.; van Eldik, R.; Liu, W.; de Visser, S. P. Chem. Eur. J. 2015, 21, 9083-9092.

89. Faponle, A. S.; Quesne, M. G.; de Visser, S. P. Chem. Eur. J. 2016, 22, 5478-5483.

90. Quesne, M. G.; Senthilnathan, D.; Singh, D.; Kumar, D.; Maldivi, P.; Sorokin, A. B.; de Visser, S. P. ACS Catal. 2016, 6, 2230-2243.

91. Jackson, T. A.; Brunold, T. C. Acc. Chem. Res. 2004, 37, 461-470.

92. Streit, B. R.; Blanc, B.; Lukat-Rodgers, G. S.; Lukat-Rodgers, K. R.; Dubois, J. L. J. Am. Chem. Soc. 2010, 132, 5711-5724.

93. Siegbahn, P. E. M. Chem. Eur. J. 2008, 14, 8290-8302.

94. Neu, H.; Baglia, R. A.; Goldberg, D. P. Acc. Chem. Res. 2015, 48, 2754-2764.

95. Chen, Z.; Yin, G. Chem. Soc. Rev. 2015, 44, 1083-1100.

96. Prokop, K. A.; de Visser, S. P.; Goldberg, D. P. Angew. Chem. Int. Ed. 2010, 49, 5091-5095. 
97. Prokop, K. A.; Neu, H. M.; de Visser, S. P.; Goldberg, D. P. J. Am. Chem. Soc. 2011, 133, 1587415877.

98. Janardanan, D.; Usharani, D.; Shaik, S. Angew. Chem. Int. Ed. 2012, 51, 4421-4425.

99. Leeladee, P.; Baglia, R. A.; Prokop, K. A.; Latifi, R.; de Visser, S. P.; Goldberg, D. P. J. Am. Chem. Soc. 2012, 134, 10397-10400.

100. Neu, H. M.; Yang, T.; Baglia, R. A.; Yosca, T. H.; Green, M. T.; Quesne, M. G.; de Visser, S. P.; Goldberg, D. P. J. Am. Chem. Soc. 2014, 136, 13845-13852.

101. Neu, H. M.; Quesne, M. G.; Yang, T.; Prokop-Prigge, K. A.; Lancaster, K. M.; Donohoe, J.; DeBeer, S.; de Visser, S. P.; Goldberg, D. P. Chem. Eur. J. 2014, 20, 14584-14588.

102. Yang, T.; Quesne, M. G.; Neu, H. M.; Cantú Reinhard, F. G.; Goldberg, D. P.; de Visser, S. P. J. Am. Chem. Soc. 2016, 138, 12375-12386.

103. Cantú Reinhard, F. G.; Faponle, A. S.; de Visser, S. P. J. Phys. Chem. A 2016, 120, 9805-9814.

104. Vardhaman, A. K.; Barman, P.; Kumar, S.; Sastri, C. V.; Kumar, D.; de Visser, S. P. Angew. Chem. Int. Ed. 2013, 52, 12288-12292.

105. Kumar, S.; Faponle, A. S.; Barman, P.; Vardhaman, A. K.; Sastri, C. V.; Kumar, D.; de Visser, S. P. J. Am. Chem. Soc. 2014, 136, 17102-17115.

106. Barman, P.; Upadhyay, P.; Faponle, A. S.; Kumar, J.; Nag, S. S.; Kumar, D.; Sastri, C. V.; de Visser, S. P. Angew. Chem. Int. Ed. 2016, 55, 11091-11095.

107. Nam, W. Acc. Chem. Res. 2007, 40, 522-531.

108. Coggins, M. K.; Kovacs, J. A. J. Am. Chem. Soc. 2011, 133, 12470-12473.

109. Zlatar, M.; Gruden, M.; Vassilyeva, O. Y.; Buvaylo, E. A.; Ponomarev, A. N.; Zvyagin, S. A.; Wosnitza, J.; Krzystek, J.; Garcia-Fernandez, P.; Duboc, C. Inorg. Chem. 2016, 55, 1192-1201.

110. Shaik, S. S. J. Am. Chem. Soc. 1981, 103, 3692-3701.

111. Shaik, S.; Kumar, D.; de Visser, S. P. J. Am. Chem. Soc. 2008, 130, 10128-10140.

112. Cantú Reinhard, F. G.; Sainna, M. A.; Upadhyay, P.; Balan, G. A.; Kumar, D.; Fornarini, S.; Crestoni, M. E.; de Visser, S. P. Chem. Eur. J. 2016, 22, 18608-18619. 
Figure captions:

Figure 1: The active site structure of TauD with the typical 2-His/1-carboxylate ligand motif and with $\alpha$-ketoglutarate $(\alpha-K G)$ and taurine bound.

Figure 2: Catalytic cycle of TauD with key intermediates highlighted.

Figure 3: Catalytic cycle of cysteine dioxygenase.

Figure 4: TD-DFT and CASSCF calculated absorption spectra of short-lived intermediates of the catalytic cycle of CDO.

Figure 5: Free energy profiles (in $\mathrm{kcal} \mathrm{mol}^{-1}$ ) for arene activation by a nonheme iron(III)hydroperoxo complex. Free energies obtained at UB3LYP/BS2+PCM//UB3LYP/BS1 as taken from Ref. ${ }^{64}$.

Figure 6: Thermochemical analysis of heterolytic and homolytic cleavage of the $\mathrm{O}-\mathrm{O}$ bond in nonheme (left) and heme (right) iron(III)-hydroperoxo complexes. Free energies in solvent given in $\mathrm{kcal} \mathrm{mol}^{-1}$.

Figure 7: Chemical structure and possible singlet and triplet spin orbital occupation of $\left[\mathrm{Mn}(\mathrm{O})\left(\mathrm{H}_{8} \mathrm{Cz}\right)(\mathrm{CN})\right]^{-}$

Figure 8: Calculated Hammett plots of para-thioanisole sulfoxidation by $\left[\mathrm{Mn}(\mathrm{O})\left(\mathrm{H}_{8} \mathrm{Cz}\right)(\mathrm{CN})\right]^{-}$on the singlet and triplet spin states.

Figure 9: DFT calculated bifurcation pathways for the reaction of a bispidine ligated manganese(III)-peroxo complex with 2-phenylpropionaldehyde. Barriers give bond lengths in angstroms and free energies are in $\mathrm{kcal} \mathrm{mol}^{-1}$. 
Figure 10: Two-parabola curve crossing diagram to rationalize nucleophilic versus electrophilic reaction mechanisms.

Figure 11: Valence bond structures for the reaction mechanism of hydrogen atom abstraction by a side-on manganese-peroxo complex.

Figure 12: Valence bond structures for the reaction mechanism for nucleophilic addition of aldehydes by a side-on manganese-peroxo complex. 